CLINICAL STUDY

\title{
Optimalization and cost management of lanreotide-Autogel therapy in acromegaly
}

\author{
Pascale Abrams, Orsalia Alexopoulou ${ }^{1}$, Roger Abs, Dominique Maiter ${ }^{1}$ and Johan Verhelst ${ }^{2}$ \\ Department of Endocrinology, University Hospital of Antwerp, Wilrijkstraat 1, B-2650 Antwerp, Belgium, ${ }^{1}$ Department of Endocrinology, UCL-St Luc \\ Hospital, Brussels, Belgium and ${ }^{2}$ Department of Endocrinology, Middelheim Hospital, Antwerp, Belgium
}

(Correspondence should be addressed to P Abrams; Email: pascale.abrams@uza.be)

\begin{abstract}
Background: Lanreotide-Autogel is a depot formulation of the somatostatin analog lanreotide used in the treatment of acromegaly. We investigated whether prolonging or shortening the interval between injections would offer any benefit.

Subjects and methods: The interval was prolonged from once every 4 weeks to once every 6 weeks when patients $(n=9)$ had normal IGF-I and GH concentrations. When patients $(n=12)$ had still elevated IGF-I or GH on the maximal dose of $120 \mathrm{mg}$ every 4 weeks, the interval was shortened to once every 3 weeks. Serum IGF-I and GH were measured after 12 and 24 weeks to allow for dose adaptation. Symptoms and tumor volume were evaluated at baseline and after 36 weeks.

Results: In seven of the nine subjects with normal IGF-I and GH, the interval could be extended to 6 weeks without loosing efficacy on IGF-I (195 vs $213 \mu \mathrm{g} / \mathrm{l}$; not significant, NS) and GH concentrations (1.4 vs $1.3 \mu \mathrm{g} / \mathrm{l}$; NS). The weekly dose could significantly be reduced (from 23.3 to $17.8 \mathrm{mg}$; $P=0.002)$. In only 1 of the 12 not-controlled patients, reducing the interval to once every 3 weeks induced normalization of IGF-I and GH.

Conclusion: In subjects whose acromegaly is well controlled using lanreotide-Autogel, prolonging the time interval between injections can often be increased 4 to 6 weeks without loss of efficacy, thereby improving the subject's comfort and reducing the cost of treatment. On the other hand, in subjects whose acromegaly is not controlled on a dose of $120 \mathrm{mg}$ every 4 weeks, reducing the interval to every 3 weeks is rarely beneficial.
\end{abstract}

European Journal of Endocrinology 157 571-577

\section{Introduction}

Uncontrolled acromegaly is associated with significant morbidity and mortality (1). The main goal of therapy is to normalize, or at least adequately control, both biochemical disease markers, insulin-like growth factor-I (IGF-I) and growth hormone (GH), allowing reversal of the mortality rate into the range of the general population. Although neurosurgery is still considered the first-line treatment for acromegaly, the cure rate in the best surgical series is estimated to be not higher than $80-90 \%$ for microadenomas and $30-50 \%$ for macroadenomas $(2,3)$. Therefore, adjuvant therapy is frequently necessary to achieve optimal IGF-I and GH control (1). External radiotherapy usually prevents tumor growth and reduces IGF-I and GH levels, but the slow onsetof action, the high incidence of hypopituitarism, and the cerebrovascular complications have minimized its role (4-6). Recent advances in the development of pharmacologic agents have permitted more efficacious medical treatment of persistent acromegaly, and these agents are also emerging as compelling options for primary therapy in selected patients (7). However, due to its long-term requirement, medical therapy has an elevated financial burden, compared with uneventful surgery or radiotherapy. Cabergoline, a long-acting dopamine agonist, appears to have a particular benefit in acromegalic patients with moderate disease activity or a tumor co-secreting prolactin $(8,9)$. Long-acting somatostatin analogs, such as octreotide and lanreotide, exhibiting a high affinity for somatostatin analog long acting (SSTR)-2, have been shown to be effective, normalizing serum IGF-I levels in up to $60 \%$ of unselected cases (10-16). The GH receptor antagonist, pegvisomant, is presently the most effective medical treatment, normalizing IGF-I secretion in about $90 \%$ of cases (17). Restraints for this treatment are the need of frequent injections and the high cost, specially if reimbursement is not provided by the social security. The limitations of the medical therapies have led investigators to develop combined drug modalities $(18,19)$ and to look for somatostatin analogs with improved SSTR-5 binding or with binding to the dopamine receptor $(20,21)$.

In this study, we first investigated whether cost reduction of somatostatin analog treatment could be achieved by prolonging the time interval between injections without loss of efficacy in patients whose 
acromegaly is adequately controlled by lanreotideAutogel. Secondly, we considered the possibility of enhancing the efficacy of lanreotide-Autogel by increasing the dose. For these purposes, the dose of lanreotideAutogel was adapted to optimize the treatment and to reduce the cost in a group of 21 acromegalic patients already receiving a 4-weekly dose of this medication for a period of 24 weeks.

\section{Subjects and methods}

\section{Subjects and study protocol}

Of the 25 subjects with active acromegaly reported in a previous study comparing the efficacy of octreotide-LAR and lanreotide-Autogel (16), 21 were included in this prospective, open, multicenter, within-subject controlled extension study. All subjects had been treated during the 12 previous weeks with lanreotide-Autogel at a fixed 4 weekly dose of $60 \mathrm{mg}(n=3), 90 \mathrm{mg}(n=3)$, or $120 \mathrm{mg}$ $(n=15)$. The dose titration in this study depended upon the measurements of age- and gender-adjusted IGF-I values and the mean of three consecutive GH determinations taken at 30-min intervals. At the start of this study, a first dose adaptation was carried out. The time interval between two injections was increased to 6 weeks in patients whose acromegaly is well controlled overall (arbitrarily defined by a normal IGF-I and a mean GH $<$ $1.7 \mu \mathrm{g} / \mathrm{l}$ ). In patients with overall poor control (IGF-I above normal and $\mathrm{GH}>2.5 \mu \mathrm{g} / \mathrm{l})$, the starting dose was increased by $30 \mathrm{mg}$ to a maximum of $120 \mathrm{mg}$ every 4 weeks or the time interval was decreased to 3 weeks in patients in whom the $120 \mathrm{mg}$ dosage was already used. In case of 'reasonably good' control (IGF-I normal and mean $\mathrm{GH}>1.7$ and $<2.5 \mu \mathrm{g} / \mathrm{l}$ ), the time interval was increased to 6 weeks and the dose was simultaneously increased by $30 \mathrm{mg}$, resulting in a comparable weekly dose. After periods of 12 and 24 weeks from baseline, a further dose adaptation was done in cases of poor control, by increasing the dose or by decreasing the time between injections.

The analysis at the end of the study was performed by taking into account the efficacy of the final dose of lanreotide-Autogel. For the purpose of comparison, the dose is reported in milligrams per week regardless of the frequency of administration. The subjects were separated into two groups: group A consisted of nine subjects receiving a final dose of lanreotide-Autogel $\leq 30 \mathrm{mg}$ per week (classical dose group) and group B consisted of 12 subjects in whom the dose of lanreotide-Autogel had to be increased to $40 \mathrm{mg}$ per week because of inadequate IGF-I and GH control with a classical dose. In each group, we compared the IGF-I and GH values and the doses of lanreotide-Autogel used at the start of the study (baseline) and at 36 weeks (final). Characteristics of both groups are given in Table 1. Only small differences between both groups were observed regarding gender distribution, age, BMI, blood pressure, duration of acromegaly, tumor size, and glycemic control (not significant, NS). At the time of diagnosis, 20 patients had a macroadenoma and one patient (in group A) had a microadenoma. Neurosurgery was significantly more often a primary treatment of choice in the notcontrolled group B, while prolonged somatostatin analog treatment was significantly more favored in the controlled group A $(P<0.05)$.

The protocol was approved by the local ethics committees of each study center, and all subjects gave written informed consent.

\section{GH and IGF-I measurements}

All fasting IGF-I and GH measurements were performed centrally by automated, two-site chemiluminescence immunoassays (Nichols Advantage IGF-I Assay and Nichols Advantage HGH Assay, Nichols Institute Diagnostics, San Juan Capistrano, CA, USA).

The sensitivity of the IGF-I assay was $6 \mu \mathrm{g} / \mathrm{l}$ and the intra- and inter-assay coefficients of variation were 5.2 and $5.7 \%$ respectively. The age-related normal serum IGF-I concentrations were 125-379 $\mu \mathrm{g} / \mathrm{l}$ (25-30 years), $114-316 \mu \mathrm{g} / \mathrm{l}$ (30-35 years), 108-301 $\mu \mathrm{g} / \mathrm{l} \quad(35-40$ years), $101-279 \mu \mathrm{g} / \mathrm{l}$ (40-50 years), $92-253 \mu \mathrm{g} / \mathrm{l}$ (50-60 years), and 83-230 $\mu \mathrm{g} / \mathrm{l}$ (60-80 years).

The calculated sensitivity of the GH assay was $0.1 \mu \mathrm{g} / \mathrm{l}$ and the intra- and inter-assay coefficients of variation were 4.8 and $5.8 \%$ respectively. GH values were expressed in terms of the first WHO International Standard (IS) 80/505 for rDNA GH, in use at the time of the assay (conversion factor for expression in terms of the second WHO IS $98 / 574$ provided by Nichols $=\mathrm{GH}$ concentration $\times 0.56$ ).

Most studies in treated acromegalics are using a $2.5 \mathrm{ng} / \mathrm{ml}$ threshold as a 'safe' GH level but emerging evidence exists that this limit might be too high and should be decreased to $2.0 \mathrm{ng} / \mathrm{ml}$ or even lower. We arbitrarily chose $1.7 \mathrm{ng} / \mathrm{ml}$ as strict cutoff value of good control. In contrast, a GH value above $2.5 \mu \mathrm{g} / \mathrm{l}$ was considered as indicative of poor control.

\section{Symptoms of acromegaly}

Five signs or symptoms of active acromegaly (headache, perspiration, asthenia, swelling of extremities, and joint pain) were self-evaluated by the subject using a fourpoint rating scale (absent $=0$, mild $=1$, moderate $=2$, and severe $=3$ ). A comparison between the symptomatology at the start and end of the study is reported.

\section{Cost of treatment}

The cost of one injection of lanreotide-Autogel in Belgium is $€ 943$ for $60 \mathrm{mg}$, $€ 1128$ for $90 \mathrm{mg}$, and $€ 1380$ for $120 \mathrm{mg}$. 


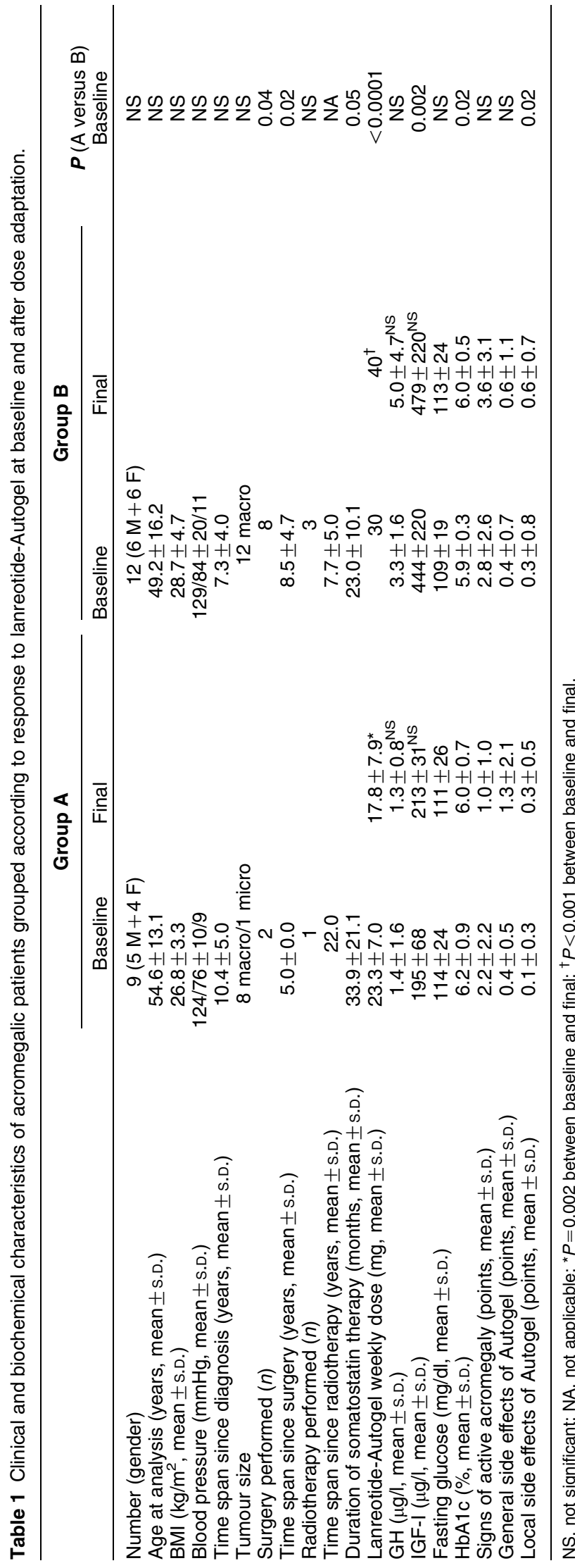

\section{Safety}

General adverse side effects of lanreotide-Autogel (nausea, gastrointestinal discomfort, and diarrhea) and local symptoms at the injection site (pain, erythema, and swelling) were recorded throughout the study. Symptoms were classified using a four-point rating scale (none $=0$, mild $=1$, moderate $=2$, and severe $=3$ ), and results were compared between the start and end of the study.

Ultrasound examination of the gallbladder was performed at the start and end of the study.

Pituitary imaging was performed at the start and end of the study, whenever residual tissue was present. The volume of the tumor was calculated using the mathematical formula of a rotating ellipsoid (34). Changes in tumor size between the start and end of the study were defined as absent $(<25 \%)$, moderate (between 25 and 50\%), or marked (more than 50\% reduction or increase).

\section{Statistical analysis}

Continuous, normally distributed variables were analyzed using an ANOVA model to compare in the same subject final values recorded at the start and end of the study. For continuous variables which even after log transformation grossly violated the normality assumptions for ANOVA, the Wilcoxon's signed-rank test was performed on the recorded differences between the start and end of the study.

\section{Results}

\section{Baseline characteristics of groups $A$ and $B$}

As could be assumed from the subdivision, the two groups showed significantly distinct characteristics regarding the weekly dose of lanreotide-Autogel $(17.8 \pm 7.9$ vs $40, P<0.0001)$ and its therapeutic efficacy on IGF-I $(213 \pm 31$ vs $479 \pm 220 \mu \mathrm{g} / \mathrm{l}$ respectively, $P<0.002)$. The clinical signs of acromegaly were more pronounced in the not-controlled group, although not in a significant manner. Lanreotide-Autogel was well tolerated since general and local side effects were scarce in both groups (Table 1).

\section{Dose adaptation in group A (disease control-classical dose)}

The dose of lanreotide-Autogel could be decreased from $60 \mathrm{mg}$ four-weekly to $60 \mathrm{mg}$ six-weekly in three subjects (A3, A5, and A8), from $90 \mathrm{mg}$ four-weekly to $90 \mathrm{mg}$ six-weekly in two subjects (A7 and A9), and from $120 \mathrm{mg}$ four-weekly to $120 \mathrm{mg}$ six-weekly in two subjects (A2 and A6). In two other subjects (A1 and A4), the dose of $120 \mathrm{mg}$ four-weekly had to be maintained. 
The calculated weekly dose of lanreotide-Autogel could be significantly decreased from $23.3 \pm 7.0$ to $17.8 \pm$ $7.9 \mathrm{mg}(P=0.002)$. This had no significant impact on IGF-I concentration $(195 \pm 68$ vs $213 \pm 31 \mu \mathrm{g} / \mathrm{l}$ before and after dose adaptation respectively; NS), nor on mean GH concentration ( $1.4 \pm 1.6$ vs $1.3 \pm 0.8$; NS).

The individual doses of lanreotide-Autogel and the IGF-I and GH responses are shown in the left panels of Figs 1 and 2 (IGF-I and GH respectively).

Nine subjects were ultimately controlled for IGF-I and GH concentrations with a weekly dose of lanreotideAutogel equal or $<30 \mathrm{mg}$. All nine subjects had already a normal IGF-I and seven had a safe GH value at baseline. One of the subjects with a slightly elevated GH concentration (A4) showed normalization without increasing the dose lanreotide-Autogel, while the dose could even be decreased in another one (A6). Overall, the weekly dose could be diminished in seven of nine subjects by prolonging the time interval between injections to 6 weeks without deteriorating the biochemical control of acromegaly.

Plasma glucose and $\mathrm{HbA1c}$ were not different from baseline (Table 1). The clinical signs of active acromegaly decreased from $2.2 \pm 2.2$ at baseline to $1.0 \pm 1.0$ at the end of the trial (NS). No significant changes in general or local side effects occurred during the study, except for a major local irritation in one subject. The number of subjects with gallstones increased from four to five. Pituitary imaging performed in seven subjects showed a moderate decrease in tumor volume in one and no changes in the remainder.

On a yearly basis, for seven of the nine subjects in whom the dose could be decreased the cost diminished by almost $34000 €$ from $137865 €$ to $103870 €$.

\section{Dose adaptation in group B (no disease control - high dose)}

The weekly dose of lanreotide-Autogel, which was adapted in all subjects (B1-12), increased significantly from 30 to $40 \mathrm{mg}(P<0.001)$. Despite this adaptation, further, although not-significant increases, in IGF-I $(444 \pm 220$ vs $479 \pm 220 \mu \mathrm{g} / \mathrm{l})$ and $\mathrm{GH}$ concentrations $(4.1 \pm 2.6$ vs $5.0 \pm 4.7 \mu \mathrm{g} / \mathrm{l})$ were observed.

The individual doses of lanreotide-Autogel and the IGF-I and GH responses are shown in the right panels of Figs 1 and 2 (IGF-I and GH respectively).

Increase of the lanreotide-Autogel dose to $40 \mathrm{mg}$ per week resulted in a normalization of both IGF-I and GH in only one subject (B9). One subject (B4) normalized GH levels without normalization of IGF-I. One subject (B11) with normal IGF-I before and after dose adaptation still maintained elevated GH levels despite this adaptation. One subject (B10) with safe GH before and after dose adaptation still maintained elevated IGF-I levels despite this adaptation. IGF-I control was lost in one subject (B3) and GH control in another one (B12). In the remaining six subjects, normalization of IGF-I or GH did not occur.

Plasma glucose and $\mathrm{HbA1c}$ were not different from baseline. The clinical signs of active acromegaly increased from $2.8 \pm 2.6$ at baseline to $3.6 \pm 3.1$ at the end of the trial (NS). No major changes in general and local side effects occurred. The number of subjects with gallstones increased from five to six. Pituitary imaging performed in seven subjects showed a moderate reduction in volume in two and an increase moderate in another two.

The yearly cost for the 12 subjects in this study receiving a 4-weekly dose of $120 \mathrm{mg}$ lanreotide-Autogel
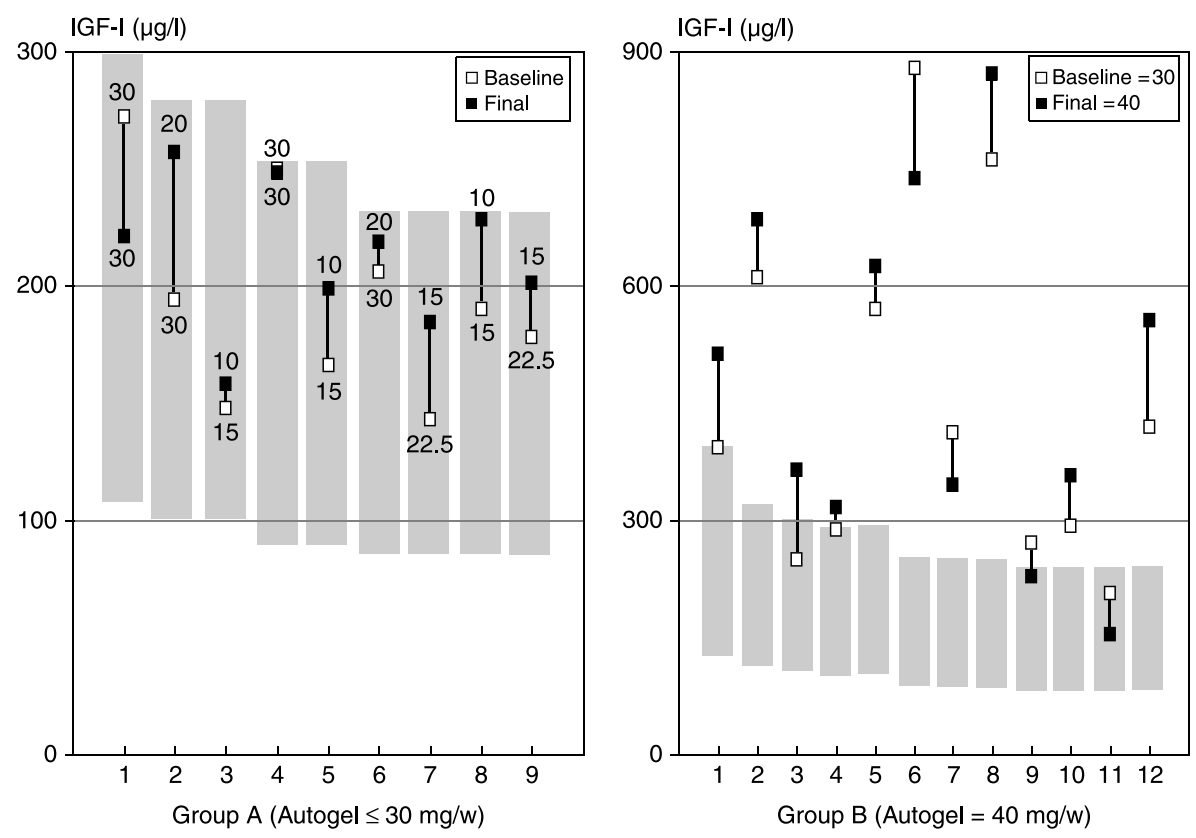

Figure 1 Serum IGF-I concentrations in acromegalic subjects responding to a dose of lanreotideAutogel equal or $<30 \mathrm{mg}$ (left panel) and the subjects requiring a dose of $40 \mathrm{mg}$ (right panel). The open squares correspond to the baseline values and the closed squares to the final values after changing of dose or time gap between injections. The numbers next to the squares indicate the weekly dose of lanreotide-Autogel. The shaded zones depict the age-adapted normal IGF-I concentrations. 

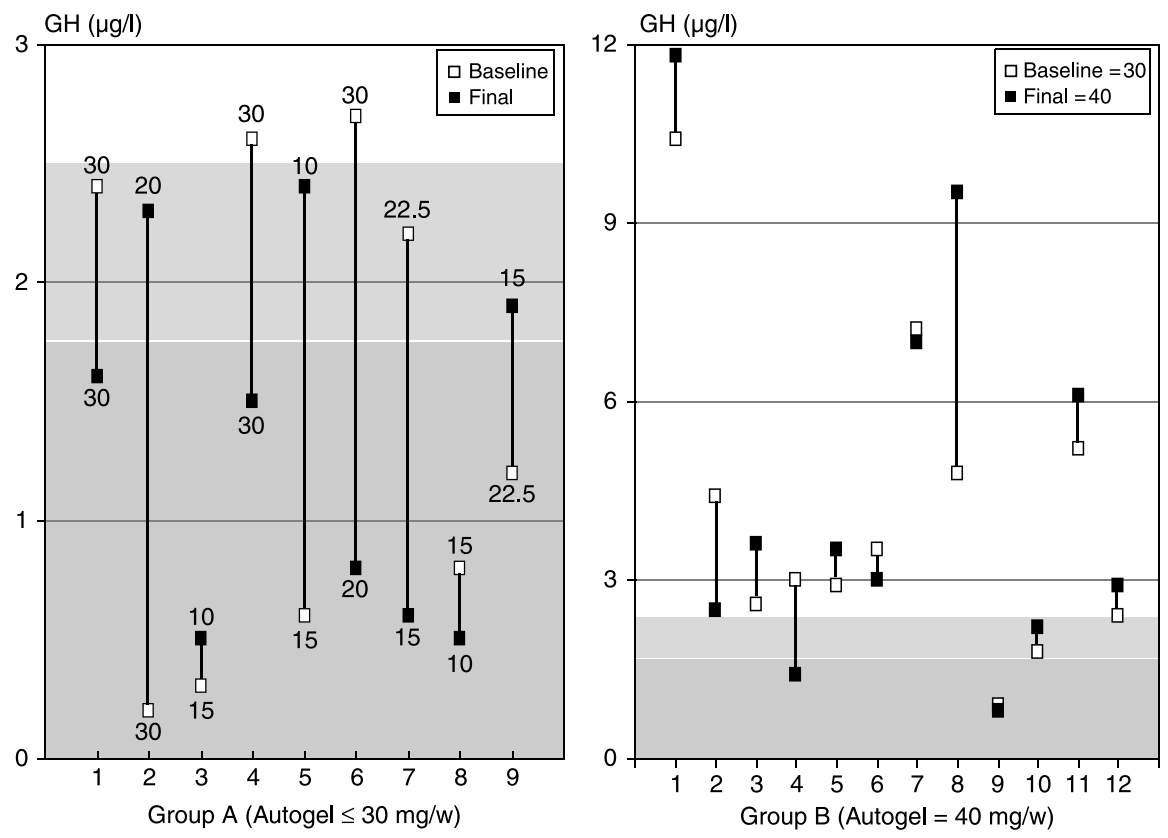

Figure 2 Serum GH concentrations in acromegalic subjects responding to a dose of lanreotide-Autogel $\leq 30 \mathrm{mg}$ (left panel) and the subjects requiring a dose of $40 \mathrm{mg}$ (right panel). The open squares correspond to the baseline values and the closed squares to the final values after changing of dose or time gap between injections. The numbers next to the squares indicate the weekly dose of lanreotide-Autogel. The shaded zones depict the safe $\mathrm{GH}$ concentration below $1.7 \mu \mathrm{g} / \mathrm{l}$ (dark grey) or $2.5 \mu \mathrm{g} / \mathrm{l}$ (light grey). would increase by $€ 71760$ from $€ 215280$ to $€ 287040$ if the dose were given 3-weekly, however it was only beneficial for one subject.

\section{Discussion}

Somatostatin analogs such as octreotide and lanreotide are acceptable therapeutic options in acromegaly since they are known to normalize IGF-I and $\mathrm{GH}$ levels in $40-60 \%$ and to induce some tumor shrinkage in 30\% of subjects $(10,11)$. These drugs are available in depot preparations in different dosages, 20-30 mg for octreotide-LAR and 60-90-120 mg for lanreotide-Autogel. The interval between injections is usually kept constant at 4 weeks. It is generally advised to regularly adjust the dose upon the serum IGF-I and GH levels in order to obtain the best effect on disease activity at the lowest price. We arbitrarily chose $1.7 \mathrm{ng} / \mathrm{ml}$ as strict cutoff value of control of disease because several retrospective studies have reported that a $\mathrm{GH}$ value of $2 \mu \mathrm{g} / \mathrm{l}$ or even lower is an appropriate therapeutic target, as values above this level are associated with increased mortality (31).

In the present study, which was an extension of a comparison study between octreotide-LAR and lanreotide-Autogel (16), we investigated whether changes in the interval between lanreotide-Autogel injections in addition to changes in the dose would offer any benefit in terms of clinical and biochemical control, subject's comfort, and cost of therapy. We could first demonstrate that in $78 \%$ of subjects, well controlled by the classical dose of $30 \mathrm{mg} /$ week or less (good responders), the interval between injections of lanreotide-Autogel could be extended to 6 weeks instead of 4 weeks without significant loss in disease control. In addition, the total dose of medication could be significantly reduced from 23.3 to $17.8 \mathrm{mg} /$ week. But even when the total weekly dose remains unchanged, prolonging the interval between injections can improve patient comfort and reduce costs. For instance, changing to dose lanreotideAutogel from $60 \mathrm{mg}$ every 4 weeks to $90 \mathrm{mg}$ every 6 weeks results in a decrease of the yearly number of injections from 12 to 8 and in a reduction of the yearly cost from $11316 €$ to $9024 €$, due to the lower relative price of the $90 \mathrm{mg}$ dosage.

The possibility of extending the interval between injections of somatostatin analogs was also reported in studies with lanreotide prolonged release, another depot form of lanreotide which is released gradually over 7-14 days after injection via biodegradable microparticles. In one study, it was shown that $27 \%$ of patients with acromegaly still had safe GH levels 3 weeks after their last injection, suggesting that the interval may be increased from once every 1 or 2 weeks to once every 3 weeks when subjects initially respond well (22). In another study, the interval between injections could even be increased to once every 4 weeks in lanreotidesensitive subjects, without altering the efficacy upon IGF-I and GH secretion (23). More recently, a large number of acromegalic subjects switched from lanreotide prolonged release to lanreotide-Autogel could remain well controlled with injections every 6 or even 8 weeks, at the condition that they were well controlled by lanreotide prolonged release every 10-14 days (24). The possibility of extending the interval between injections from once every 4 to once every 6 weeks or even longer without loosing efficacy has also been reported with octreotide-LAR $(22,25,26)$. After a total 
of 12 months of treatment with lanreotide-Autogel, a true steady state was still not clearly obtained in some of our patients. Several studies have shown indeed that serum GH and IGF-I levels may continue to progressively decline during long-term treatment with somatostatin analogs $(32,33)$.

The reasons why IGF-I and GH levels remain under control after prolonging the interval are probably twofold. First, in a pharmacodynamic study in 24 healthy volunteers, significant levels of lanreotide could still be found at day 56, indicating continued drug activity beyond 4 weeks (27). Secondly, IGF-I and GH levels once adequately suppressed with somatostatin analogs may need 4-12 weeks before starting to rise again (28).

In the second part of the present study, we examined whether shortening the dose interval of lanreotideAutogel would offer any advantage in terms of control of IGF-I and GH levels in subjects not controlled by the classical dose of $120 \mathrm{mg}$ 4-weekly. Despite increasing the weekly dose from 30 to $40 \mathrm{mg}$, only one of the subjects $(8 \%)$ experienced any benefit from reducing the interval between injections to 3 weeks. The clinical experience with high-dose somatostatin analogs remains limited, but, similarly to lanreotide-Autogel, a poor therapeutic response with octreotide-LAR has been observed. Seven acromegalic subjects, included in a series of 36 treated by octreotide-LAR, received a monthly dose of $40 \mathrm{mg}$, but only one achieved a normalization of IGF-I and a safe GH concentration (29). These findings concur with the concept that partial or complete resistance of somatotrope adenomas to somatostatin analogs is usually not related to inadequate dosing but rather to a deficient number or insensitive type of receptors on the cell membrane (30).

In conclusion, this open multicenter study shows that in well-controlled subjects prolonging the time interval between two injections of lanreotide-Autogel from 4 to 6 weeks can be done in a majority of subjects without loosing efficacy, thereby improving their comfort and reducing the cost of treatment. On the other hand, in not-controlled subjects on the maximal dose of $120 \mathrm{mg}$ 4-weekly, a further increase of the dose will rarely improve the biochemical control.

\section{Acknowledgements}

The authors wish to thank the Ipsen Company for generously supplying lanreotide-Autogel.

\section{References}

1 AACE Guidelines. American association of clinical endocrinologists medical guidelines for clinical practice for the diagnosis and treatment of acromegaly. Endocrine Practice 200410 214-225.

2 Melmed S. Acromegaly. In The Pituitary, edn 2 (ch. 11), pp 419-454. Ed. S Melmed, Massachusetts: Blackwell Science Inc, 2002.
3 Stewart PM. Current therapy for acromegaly. Trends in Endocrinology and Metabolism 200011 128-132.

4 Monson JP. Is there still a role for radiotherapy in acromegaly? Neuroendocrinology 200683 269-273.

5 Powell IS, Wardlaw SL, Post KD \& Freda PU. Outcome of radiotherapy for acromegaly using normalization of insulin-like growth factor I to define cure. Journal of Clinical Endocrinology and Metabolism 200085 2068-2071.

6 Epaminonda P, Porretti S, Cappiello V, Beck-Peccoz P, Faglia G \& Arosio M. Efficacy of radiotherapy in normalizing serum IGF-I, acid-labile subunit (ALS) and IGFBP-3 levels in acromegaly. Clinical Endocrinology 200155 183-189.

7 Muller AF \& van der Lely AJ. Pharmacological therapy for acromegaly. A critical review. Drugs 200416 1817-1838.

8 Biller BMK, Molitch ME, Vance ML, Baker Cannistrato K, Davis KR, Simons JA, Schoenfelder JR \& Klibanski A. Treatment of prolactinsecreting macroadenoma with the once-weekly dopamine agonist cabergoline. Journal of Clinical Endocrinology and Metabolism 1996 $812338-2343$.

9 Abs R, Verhelst J, Maiter D, Van Acker K, Nobels F, Coolens JL, Mahler C \& Beckers A. Cabergoline in the treatment of acromegaly: a study in 64 patients. Journal of Clinical Endocrinology and Metabolism $1998 \mathbf{8 3} 374-378$.

10 Freda PU, Katznelson L, van der Lely AJ, Reyes CM, Zhao S \& Rabinowitz D. Long-acting somatostatin analog therapy of acromegaly: a meta-analysis. Journal of Clinical Endocrinology and Metabolism 200590 4465-4473.

11 Verhelst JA, Pedroncelli AM, Abs R, Montini M, Vandeweghe MV, Albani G, Maiter D, Pagani MD, Legros JJ, Gianola D, Bex M, Poppe K, Mockel J \& Pagani G. Slow release lanreotide in the treatment of acromegaly: a study of 66 patients. European Journal of Endocrinology 2000143 577-584.

12 Stewart PM, Kane KF, Stewart SE, Lancranjan I \& Sheppard MC. Depot long-acting somatostatin analog (Sandostatin-LAR) is an effective treatment for acromegaly. Journal of Clinical Endocrinology and Metabolism $1995803267-3272$.

13 Giusti M, Gussoni G, Cuttica CM \& Giordano G. Effectiveness and tolerability of slow release lanreotide treatment in active acromegaly: six-month report on an Italian multicenter study. Italian Multicenter Slow Release Lanreotide Study Group. Journal of Clinical Endocrinology and Metabolism 199681 2089-2097.

14 Caron P, Morange-Ramos I, Cogne M \& Jaquet P. Three year followup of acromegalic patients treated with intramuscular slowrelease lanreotide. Journal of Clinical Endocrinology and Metabolism 199782 18-22.

15 Lancranjan I \& Atkinson AB. Results of a European multicentre study with Sandostatin LAR in acromegalic patients. Sandostatin LAR Group. Pituitary 19991 105-114.

16 Alexopoulou O, Abrams P, Verhelst J, Poppe K, Velkeniers B, Abs R \& Maiter D. Efficacy and tolerability of lanreotide autogel therapy in acromegalic patients previously treated with octreotide LAR. European Journal of Endocrinology 2005151 317-324.

17 van der Lely AJ, Hutson RK, Trainer PJ, Besser GM, Barkan AL, Katznelson L, Klibanski A, Herman-Bonert V, Melmed S, Vance ML, Freda PU, Stewart PM, Friend KE, Clemmons DR, Johannsson G, Stavrou S, Cook DM, Phillips LS, Strasburger CJ, Hackett S, Zib KA, Davis RJ, Scarlett JA \& Thorner MO. Long-term treatment of acromegaly with pegvisomant, a growth hormone receptor antagonist. Lancet $2001 \mathbf{3 5 8} 1754-1759$.

18 Selvarajah D, Webster J, Ross R \& Newell-Price J. Effectiveness of adding dopamine agonist therapy to long-acting somatostatin analogues in the management of acromegaly. European Journal of Endocrinology 2005152 569-574.

19 Feenstra J, de Herder WW, ten Have SM, van den Beld AW, Feelders RA, Janssen JA \& van der Lely AJ. Combined therapy with somatostatin analogues and weekly pegvisomant in active acromegaly. Lancet 200513 1644-1646.

20 van der Hoek J, de Herder WW, Feelders RA, van der Lely AJ, Uitterlinden P, Boerlin V, Bruns C, Poon KW, Lewis I, Weckbecker G, Krahnke T, Hofland LJ \& Lamberts SW. A singledose comparison of the acute effects between the new 
somatostatin analog SOM230 and octreotide in acromegalic patients. Journal of Clinical Endocrinology and Metabolism 2004 89 638-645.

21 Jaquet P, Gunz G, Saveanu A, Dufour H, Taylor J, Dong J, Kim S, Moreau JP, Enjalbert A \& Culler MD. Efficacy of chimeric molecules directed towards multiple somatostatin and dopamine receptors on inhibition of $\mathrm{GH}$ and prolactin secretion from $\mathrm{GH}$-secreting pituitary adenomas classified as partially responsive to somatostatin analog therapy. European Journal of Endocrinology 2005153 135-141.

22 Jenkins PJ, Akker S, Chew SL, Besser GM, Monson JP \& Grossman AB. Optimal dosage interval for depot somatostatin analogue therapy in acromegaly requires individual titration. Clinical Endocrinology 200053 719-724.

23 Caron P, Tabarin A, Cogne M, Chanson P \& Jaquet P. Variable growth hormone profiles following withdrawal of long-term $30 \mathrm{mg}$ slow-release lanreotide treatment in acromegalic patients: clinical implications. European Journal of Endocrinology 2000142 565-571.

24 Lucas T \& Astorga R. Spanish-Portuguese Multicentre Autogel Study Group on acromegaly. Efficacy of lanreotide Autogel administered every 4-8 weeks in patients with acromegaly previously responsive to lanreotide microparticles $30 \mathrm{mg}$ : a phase III trial. Clinical Endocrinology 200665 320-326.

25 Biermasz NR, van den Oever NC, Frolich M, Arias AM, Smit JW, Romijn JA \& Roelfsema F. Sandostatin LAR in acromegaly: a 6-week injection interval suppresses GH secretion as effectively as a 4-week interval. Clinical Endocrinology 200358 288-295.

26 Turner HE, Thornton-Jones VA \& Wass JA. Systematic doseextension of octreotide LAR: the importance of individual tailoring of treatment in patients with acromegaly. Clinical Endocrinology $200461224-231$.

27 Antonijoan RM, Barbanoj MJ, Cordero JA, Peraire C, Obach R, Valles J, Cherif-Cheikh R, Torres ML, Bismuth F \& Montes M.
Pharmacokinetics of a new Autogel formulation of the somatostatin analogue lanreotide after a single subcutaneous dose in healthy volunteers. Journal of Pharmacy and Pharmacology 2004 56 471-476.

28 Stewart PM, Stewart SE, Clark PM \& Sheppard MC. Clinical and biochemical response following withdrawal of a long-acting, depot injection form of octreotide (Sandostatin-LAR). Clinical Endocrinology 199950 295-299.

29 Colao A \& Ferone D. Long-term effects of depot long-acting somatostatin analog octreotide on hormone levels and tumor mass in acromegaly. Journal of Clinical Endocrinology and Metabolism $2001862779-2786$.

30 Bronstein MD. Acromegaly: molecular expression of somatostatin receptors subtypes and treatment outcome. Frontiers of Hormone Research 200635 129-134.

31 Sheppard MC. GH and mortality in acromegaly. Journal of Endocrinological Investigation 200528 75-77.

32 Jallad RS, Musolino NR, Salgado LR \& Bronstein MD. Treatment of acromegaly with octreotide -LAR extensive experience in a Brzilian institution. Clinical Endocrinology 200563 168-175.

33 Colao A, Ferone D, Marzullo P, Cappabianca P, Cirillo S, Boerlin V, Lancranjan I \& Lombardi G. Long-term effects of depot long-acting somatostatin analog octreotide on hormone levels and tumor mass in acromegaly. Journal of Clinical Endocrinology and Metabolism $2001862779-2786$.

34 Di Chiro G \& Nelson KB. The volume of the sella turcica. American Journal of Radiology 1962 87 989-1008.

Received 13 August 2007

Accepted 3 September 2007 